CONCRETE RAILROA BRIDGE AT DANVILLE.

THE increasing utilization of reinforced coilcrete is nowhere more manifest than in railway construction work. A recent example of concrete bridge structures Cincinnati, Chicago and St. Louis Railway, at Danville, Cincinnati, Chicagc and St. Louis Railway, at sanville, rather unusual design as well. The bridge is part of the complete reconstruction of the Cairo division which, nection between the coal fields of Indiana and Illinois nection between the coal fields of Indiana and Thinois and Chicago. The valley of the Salt Fork of the Vermilion River which the line crosses is about half a mile wide and from sixty-five to ninety feet below the grade of the tracks, the north side being on a steep slope. The Salt Fork flows adjacent to the south side of the valley, which is formed by a line of precipitous bluffs some 130 feet above the bed of the stream. The brige crosses the salt Fork with one end abutting valley is traversed by means of a fill 60 to 80 feet high and of sufficient width to carry two tracks.

and of sufficient width to carry two tracks. span in the middle and two of 80 feet span at each end span in the mide, and two of 80 feet span at each en carry the central arch, each of which supports one end of an 80 -foot arch as well. smaller arches are carried by the bridge abutments.

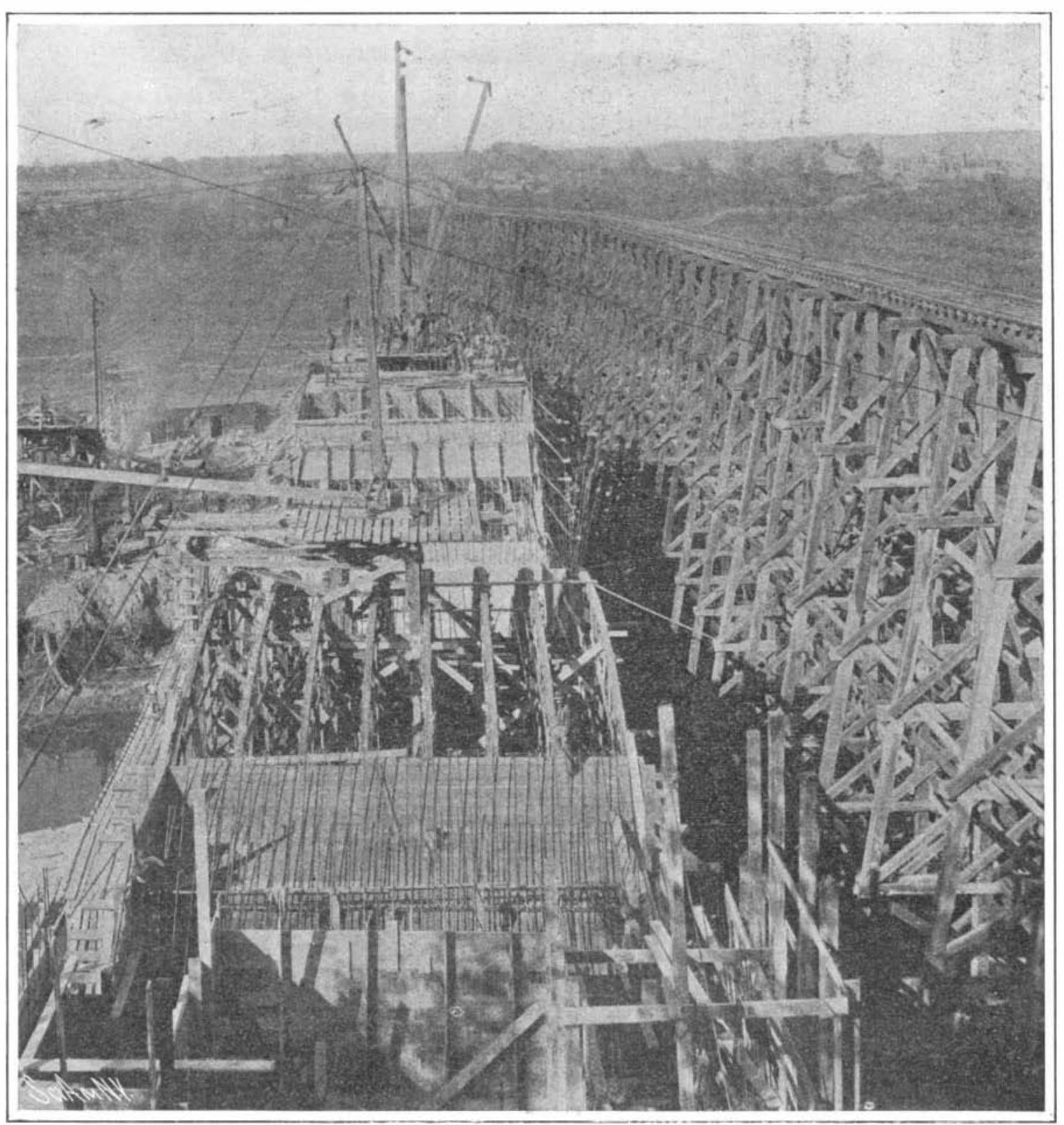

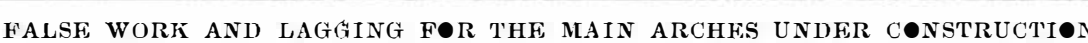

CONCRETE RAILROAD ERIDGE AT DANVILLE, ILL

The 100-foot arch has a rise of 40 feet, while the smaller arches have rises 10 feet less. The difference of the ises is equalized by a corresponding difference in the height of the springing lines above the bed of the rails are located at a height of nearly 20 feet above the extrados of the crown of the arches, and the track rest directly on a five-foot earth cushion carried by the bridge. Series of transverse arches about 2 feet thick at the crowns, and having spans of 8 feet, are carried by the main arches. Usually between the bot tom of the earth fill and the extrados of the main arches are longitudinal spandrel walls with the filling between. In this case these are replaced by the series of transverse arches, the crowns of which are in the same horizontal plane and carry a lengitudinal coping between which is located the earth filling.

The entire structure above the springing lines is reinforced by means of a corrugated bar system in the usual manner. The series of transverse spandrel arches is built in three sections, one over each main arch ring, and the arches in each section are tied together y reinforcements, while expansion joints separate the sections one from the other. At all the possible, so that the contact between the arljacent faces

* Specially prepared for the Scientific AmERICAN SUPPLEMENT.

of the joints is made only through the rails embedde in those faces, which are separated by layers of felt space at the top being filled with asphalt

The channel piers above the arch rings of the main arches are hollow, each of the sides being formed by one of the bench walls, the top of which carries an expansion joint. The ends are each iormed by pilaster and formed of reinforced concrete slabs nearly 60 feet long placed on the end.

The footings of the channel piers are carried down ten feet into the shale formation of which the bridge is built, while that of the north abutment is carrie teep) bank of the valley with its top about 12 feet below he springing line of the south arch. The back porton of this footing rests thirty-six feet below the nathalf is six feet above the rock, as the thrust from the arch reduces the load on that portion.

As soon as the footings of the piers and abutments the congleted, the construction was carried ul) to the same time the false work and centering for the enter arch vere being erected. The false work for each of the three arches comprised six transverse bents, were carrie up in 22 -foot stories with caps a whe wooden structures were thoroughly 
town with a clear atmosphere. His argument falls to the ground when we remember that a smokeless chimney is not inco
boiler service.

Other objectors are those who have made attemptsmore or less earnest and intelligent-to stop the been only half-hearted, but in others much money has been spent in misdirected effort. Many such people been spent in misdirected effort. Many such people
believe that the smoke cannot be stopped, and that it is useless to try.

What is smoke, anyway, and what causes it?

The constituents of all fuels may be classified as volatile matter, fixed carbon, and ash. The ash is large as regards smoke except that when present in fires, necessitating frequent cleaning, which is always detrimental. The fixed carbon, with which we are maining constituent, the volatile matter, occurs in large percentages in our western fuels, and to it the

When a fuel rich in volatile matter is charged into a furnace, the volatile matter is first set free as a
gas, principally in the shape of hydro-carbons. Part of these are of the olefiant series, and are dissociated at a red heat. Part of the carbon is set iree, and, i unconsumed, it passes off as smoke. It is possible to
burn this free carbon, if sufficient oxygen is present, and the temperature is high. Failing in either of these conditions there will be a smoke.

The free carbon in the densest smoke is very small, rom one-sixth to as false all claims of fuel saving due to consuming the smoke. The best furnaces, however, do make savings in fuel, not because they burn the smoke, but because improved construction and better engineering details bring about more favorable furnace conditions. The saving is often more than sufficient to pay a good interest on their cost, besides repairs and maintenance.

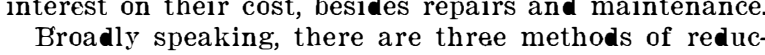
ing smoke: First, the closing down of smoke-making plants; second, the use of smokeless fuels; third, the Heric af it may seem, much

plished by the actual'shutting down of peen accomplants. A few tories, each with its smoke-making boiler. To-day such plants are operated by electric motors, supplied with power from central stations located at a distance and provided with smoke-preventing apparatus. Many buildings get their entire service of light and power the street mains, operating their boilers only may be expecte to grow as electricity becomes may be expected to grow as electricity

Much has been done in smokeless fuels, particularly for heating in the residence districts, and for many average good citizen that he will, if necessary, go to some expense to aid in beautifying his city. This, however, could not be expected under steam boilers, however, could not be expected under steam boilers,
which are the largest smoke producers. It was hoped that oil from the Texas fields could be introduced at something like reasonable cost, but present rates are prohibitive. Oil has many advantages, however which would justify a considerable increase in
cost over coal. In addition to solving the smoke problem it greatly reduces the labor charge, can be problem it greatly reduces the labor charge, can be mits an increase in the working capacity of the plant. On the other hand, however, the elements of a general way what may be done under boilers with prepared a table some time ago, based on St. Louis prices ruling before the recent advances. No claim is made for the absolute accuracy of the figures, but they are believed to be fairly reliable-relatively, at least. are out of reach in cost, except possibly as the use of powdere coal may be developed.

The deliveries in this table are assumed to be on per gallon, and at the same time cost 3 cents per gal lon, $21 / 2$ cents of which was freight. This price has since been raised, but even at these figures it falls short of competing with coal, even after adding 40 to 50 cents per ton for handling the coal and ashes. The it under boilers, it be used in oil engines of the Diesel or other modern type, which consume about $3 / 4$ pound
of oil per I. H. P hour. The ordinary Corliss engine of oil per I. H. P. hour. The ordinary Corliss engine hour. At these figures the fuel cost would be practically the same for oil as for coal.

In the table it is assumed that the powdere
coal is made from ordinary slack, at an additional cost of 35 cents per ton for powdering. will be offset by the saving in labor for coal and ash handling.

After all, however, our greatest hope for relief lies in burning ordinary fuels smokelessly. As the worst
offenders are the steam boilers, they only will be disoffenders are the steam boilers, they only will be discussed. Devices without number have been invented
for this purpose, but, unfortunately, most of them have failed to meet the exacting requirements of regu. lar service.

It should be remembered that a good ordinary boiler furnace without a special device can be so handled as to greatly reduce the smoke, provided, of course, it is somebody's patent furnace. Nor will the installation of improved apparatus of itself control the smoke. A good draft are essential to a good smoke record. Such good draft are essential to a good smoke record. Such
a furnace, skillfully fired, will make no serious smoke when working up to, say, two-thirds of its rated caWhen working up to, say, two-thirds of its rated ca-
pacity. By skillful firing is meant the charging of pacity. By skillful firing is meant the charging of fuel, particularly if the coking system of firing is used. The firing of consecutive doors, at long intervals, with large quantities of fuel, and by the sprinkling method, is respor.

If the furnace, however, is not well designed, or is If the furnace, however, is not well designed, or is
overworked, no amount of skill or care will keep the overworked, no amount of skill or care will keep the
smoke within bounds. In such cases resort must be had to special apparatus. Successful processes may be divided into five classes:

First, Steam Jets.-These are the simplest devices in use, and can be put together by any engineer at small expense. Sometimes they are placed under the they are alove the they are above the grate, immediately over the fire doors or in the side walls, discharging backward or across and slightly downward. The jet draws in air the fire, where it meets the gases being given off by the disintegrating fuel.

Devices of this character have come into extensive use. They are reasonably effective in reducing smoke, but are not usually economical in fuel. The jets are turn them on at the time of firing and then shut them off in two or three minutes, after the fresh fuel has been ignited. In some devices this is done automatically, the act of opening the fire door turning on the jet admitting steam and air, and clockwork or dashpot mechanism gradually closing it.

Second, Coking Furnaces or Firebrick Arches.These come next in first cost, and are capable of giving almost perfect results in smoke abatement if properly designed and intelligently operated. The fire-box ing surface, and can therefore be maintaine at high ing surface, and can therefore be maintaine at high
temperature. Contracte checker work, or throat areas, insure a thorough mixture of air, which is often preheated. These are built in many forms, many of which are capable of burning very inferior fuels. They reasonably uniform. The objections are that some

\begin{tabular}{|c|c|c|c|c|c|}
\hline Fuel. & 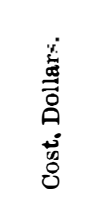 & 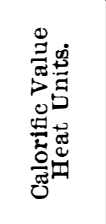 & 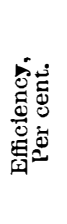 & 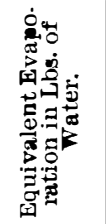 & 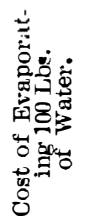 \\
\hline Fuel gas.. & $\begin{array}{l}\text { Per } 10000 \\
\text { Cu. Ft. } \\
\text { O.10. } \\
\text { Per ton }\end{array}$ & $\begin{array}{l}\text { Per } 11000 \\
\text { Cu. Ft. } \\
240,0100\end{array}$ & 80 & $\begin{array}{l}\text { Per } 1000 \\
\text { Cu. Ft. } \\
198.8\end{array}$ & $\begin{array}{l}\text { Cents. } \\
5(1) 30\end{array}$ \\
\hline 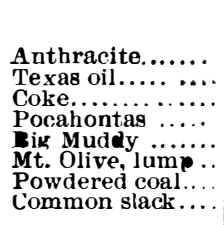 & $\begin{array}{c}\text { of } 2000 \\
\text { Lb. } \\
6.75 \\
8.80 \\
4.50 \\
4.75 \\
2.50 \\
1.60 \\
1.25 \\
0.90\end{array}$ & $\begin{array}{c}\text { Per Lb. } \\
14,000 \\
15,950 \\
12,510 \\
13,300 \\
12,200 \\
11,200 \\
10.000 \\
10,000\end{array}$ & $\begin{array}{l}75 \\
80 \\
70 \\
72 \\
68 \\
65 \\
80 \\
60\end{array}$ & $\begin{array}{c}\text { Per Lb. } \\
10.87 \\
13.27 \\
905 \\
990 \\
8.57 \\
7.53 \\
8.28 \\
6.20\end{array}$ & $\begin{array}{l}31.08 \\
30.56 \\
24.87 \\
2400 \\
1460 \\
10.62 \\
755 \\
7.25\end{array}$ \\
\hline
\end{tabular}

forms require an increase of space, and the brickwork, repairs may be large. These objections hower have been very largely remedied in the best types. There will usually be a material saving of fuel over erated.

Third, Down-Draft Furnaces.-These have proved extensive use, particularly where excessive demands for overwork are frequently made.

In the Hawley, one of the best known forms, there are two grates, one above the other. The upper grate is a row of water tubes, single or staggered, so connected as to form part of the circulation system of the boiler. Grates of the ordinary pattern would not withstand the high temperatures. The tubes are inclined upward to the rear to insure rapid circulation. The space above the rear drum is closed off, and the
gases must make their exit downward through the bed of fuel. Considerable partly burned fuel falls to the lower grate, where its combustion is completed under very favorable conditions. The two flames unite at the rear of the grates, forming a throat through which to is almost impossible for the particles of free carbon to pass unconsumed. Somewhat greater draft is
usually required for this furnace than for the common setting. Most of the air require for combustion enters through the doors above the upper grate, a small amount being admitted under the lower grate. The furnace is independent of the skill or ignorance of the
fireman to greater degree than many others. The objections are its first cost, and the fact that it is part jections are its first cost, and the fact that it is part
of the present system of the boiler. With bad water or careless or insufficient handling, there is great liability to tube and drum repairs. It usually effects a considerable saving in fuel.

Fourth, Automatic Stokers, with which may be classed chain grates and underfeed devices. These modern plants. While they are built in many forms, they all operate on the same principle-that of feeding the coal automatically to the grates in continuous the use of the finer grades of coal, such as nut, pea, or slack. In many localities there is a surplus of this raising the price and reducing the supply. Many recent stoker plants are provided with crushers to permit the use of the larger sizes of coal when necessary. When accompanied by coal handling and storage plants the automatic stoker reduces the labor require in the fireroom, and this arrangement has been adopted in many large modern plants. The ability of the stoker to maintain practically uniform steam pressure, and quirements, are features which have contributed largequirements, are

The objections to automatic stokers are: First, their great cost; second, the complication of parts and the necessity of repairs; third, the steam required to operate them. Under proper conditions there is a jections named are not serious is shown by the fact that their use is constantly increasing. The fuel to be burned should have expert study, however, before a evice of this kind is selected, as they are not equally well adapted to all fuels. Some do not respond to fluctuating loads,
types of furnaces.

Fifth, Powdered Fuels.-These have recently at tracted much attention, having for years been employed successfully in rotary cement kilns, and more ments along this line have been under way for some time in European countries with considerable success. In the most satisfactory devices the coal is reduced to an almost impalpable powder, and is then forced into the furnace under pressure, exactly as would be done this fuel is the fact that it may be made of slack or mine waste, which can be had at very low cost. While the apparatus for burning fuel is simple and inexpensive, the plant necessary for preparing the fuel is somewhat elaborate. As the fuel is explosive and liable to spontaneous combustion, it cannot be stored or handled in quantities, but should be used as fast as made. This would seem to call for a powdering plant at each point of use. There is reason for hoping, nevertheless, that good results may be looke for in hot distant future.

ot permit a discussion of all the methods which have been proposed, but the foregoing covers in a general way the devices which have been plete, however, without mentioning doukle combustion furnaces, and mechanical draft, which has come into limited use with encouraging results, both alone and in combination with others of the above named types. The classifications enumerated above are not al ways clear and distinct, as the types named are often found in combination. The fire-brick arch, for instance, is nearly always found in combination with the stoker, and often with the steam jet.

The fireboxes of locomotives and of steamboats require special treatment, but brick arches and steam is done when the two are combined. Some experiments have also been made with downdraft furnaces, ments have also been made with downdraft furnaces, locomotives and is already in extensive use where the permit. It is urgently reconmended that possible.

I am unhesitatingly of the opinion that at least one - usually more-of these devices is applicable successfully to every smoke-making boiler, and that, too, without hardship. Great care, however, must be exercised; properly adapted to the service, second, in seeing that it is carefully applied, so as to be reliable and durable, ind, third, that it is intelligently operated and maintained. The last is perhaps the most important of
the three. No apparatus, however efficient, can be expected to run itself. Give it a chance; see that it is taken care of and kept in repair, and not abused.

Incidentally the smoke-abatement movement has led to a closer study of boiler conditions, with the result ventilation, and general efficiency, is a creditable piece of engineering. It is entitle to be given at least as much attention, both by the designing and the operating engineer, as any other part of the plant. Hardly less important is the proper care and management of the boilers, and particularly of the fire itself. A good fireman should be encouraged. It pays to keep a good man, even at an advance in salary.

The following directions regarding intelligent methods of firing with a view of securing efficient and smokeless performance may be of interest:

Fire frequently and in small quantities. Break up the lumps to the size of a man's fist. Carry a level ire over the entire grate surface, not too
thin or bare spots. Keep the fires

Fire one door at a time, and wait until that fire is in good shape before charging the other door. Keep as possible.

Fire not over three shovelfuls per door to begin with. If this makes no serious smoke, increase to four smoke from the chimney shows that the limit has been reached.

Immediately after each firing leave the fire door slightly ajar for three or four minutes,

Our sympathy goes out to that individual who com. plained in a newspaper recently that the soot from the 
smoke so soiled the snow that he could not play snow ball, as in childhood's happy days. Nor can we answe that individual who expects the smoke department to
do away with our river fogs. More interesting but even less tractable, is our friend who, when the banquet is over and cigars lighted, dares us to do ou worst in preventing smoke.

Seriously, however, it is not a losing fight. Mos cities now have strict ordinances controlling the smok question, and more or less effort is being made towar their enforcement. As a rule, the courts are sustaining these laws. Some eastern cities, among them New York and Washington, prohibit the use of soft coal altogether, and I am informe that it is an offense in New York to even have it on the premises. More good. however, is done by moral suasion than by legal procedure, appealing to the civic pride of the average good citizen, and pointing out that the best method insure a fuel economy amply justifying the original outlay.

Mishaps and discouragements are not unknown in the work, but the appeal to good citizenship, the education of the public, and-more than all-keeping ever lastingly at it, will surely bring relief to any smoke-

\section{ALCOHOL AS A FUEL}

The passage of the "denatured" alcohol bill is likely to have a somewhat important effect upon power production upon a small scale. The fact is that alcohol, in spite of a thermal value more than 30 per cent below that of gasoline, has still some practical advantages of a very valuable character. During the many hearings upon the bill much important information was elicited. It seems to be generally agreed that in an engine of given cylinder dimensions and speed alco hol, when properly used, will produce a greater outpu than gasoline-in the opinion of one of our best-known engine builders, to the extent of some 20 per cent. The gain is mainly due to the greater compression at whin it is possible to work the alcohol without producing auto-lgnition, hence the gieater the expansive action obtained, the lower the temperature of the rejected gases and the higher the thermal effolency. It is understood that with a proper engine the thermal enclency may be ralsed to and above 30 per cent, 10 per cent lower. In point of safety, too, the ance 10 per cent lower. In point of safety, too, the alcoho has a very considerable advantage in that it has a very much lower flashing point than any petroleum product that can be readily worked in an internal combustion engine. Of course, even crude petroleum can be so carber

pale-blue flame that radates little heat and produces no soot. Its heat is delivere

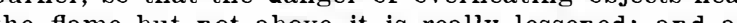
the flame but not above it is really lessened; and an alche resists, since the fuel floats on water insteal of

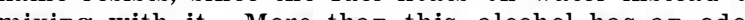
at least inofensive, while gasoline has an efluvium which Coleride in , whme "the two and seventy which Coleridge in enumb ", ef coventy have placed quite in a class by itself. So much for bave in the open air or in storage. In engines it works in the open air or in storage. In engines it which the main product is water vapor. Less easily vaporize than galine it still is readily enous malyvaporized than gasoline it still is readily enough man As to actual costs in operating alcohol engines, data differ somewhat. A few engines have been sent from differ sontry to A few engin this country to to 12 , where hood enough for the purpose. good enosoline dynamical value per gallon. Prior to the passage the recent bill such spirit would have carried a probibitive tax some 44 per gallon. hibitive tax, some su pertra have to cary some extra charge for denaturizing. Wood sive the the alcohol itself, and pyridine the exper " is far from cheap and has a most infamous odor. process of there is room for imperene the bill pross of denturization, and the bill goes into effect can be utilized to good purpose in the purpose still leaves a fair margin of cost in favor of alphol when the manufacture gets fairly faver of alcohol when the manufacture gets fairly unde way. All sorts of vegetable waste, such as refuse from he beet sugar process, can be un for alcohol making, as well as surplus grain in times of exceptional watch should be kept lest some of the chief gains we bill be bullifiept lest some of the chief gains of such as would practically throw the industry into the hands of a monopoly. Given the spirit at anything like the price claimed by its advocates, and we would seem to have a fuel peculiarly well adapted for many cases of small power production, for subsidiary heating purposes so important in many industries, and for auxiliary residence heating. To make the best use of it in explosion engines, special machines will have to be produced, although foreign experience shows that the same engine can use either alcohol or gasoline without so great losses as have sometimes been alleged. One large German maker gives the difference in weight of fuel as about 10 per cent in favor of gasoline in an engine adapted for the use of either. However, the special engine is the proper thing to use for high econ-

omy, and it will come along quickly enough when there is a demand for it. It would seem, too, that it should be easier to make a successful two-cycle engine or alcohol than for gasoline on account of the cleane combustion. It is hardly to be expected that alcohol can be use economically for power production on any arge scale, producer gas being too severe a competitor.

In the duplex motor we have a piston which is made double, as will be notice in the section. The upper part of the piston has a smaller diameter and works in the top cylinder, $A$, while the lower part is enlarged to form a second piston, working in a second cylinder of larger diameter, $B$. The two cylinder chambers are so proportioned as to have an equivalent capacity.
Thus we find a single piston moving in two distinct

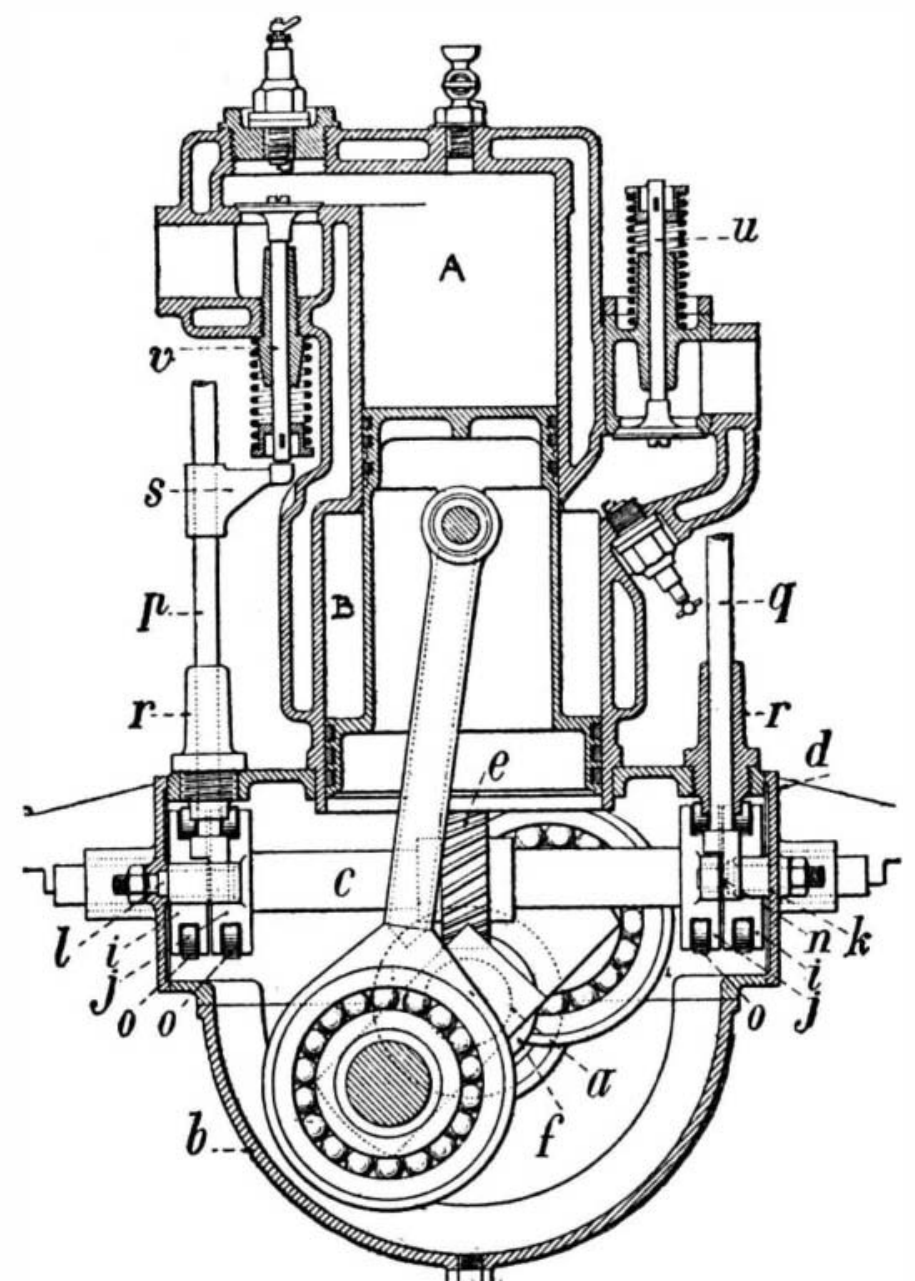

FIG. 1.-VER.TICAL SECTION OF ONE OF THE CYLINDERS.

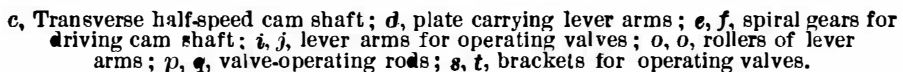

that one is employing a material which can be reproduced in the cycle of the seasons insteal of drawing upon the stores energy that is so rapidy being depleted-Electrical World.

A NEW DUPLEX FOUR-CYCLE GASOLINE MOTOR. By the Paris Correspondent of Scientific American. THE Boudreaux-Verdet motor, which has lately been placed on the market in Paris, is of somewhat novel design. It is intended to obtain the advantages of a

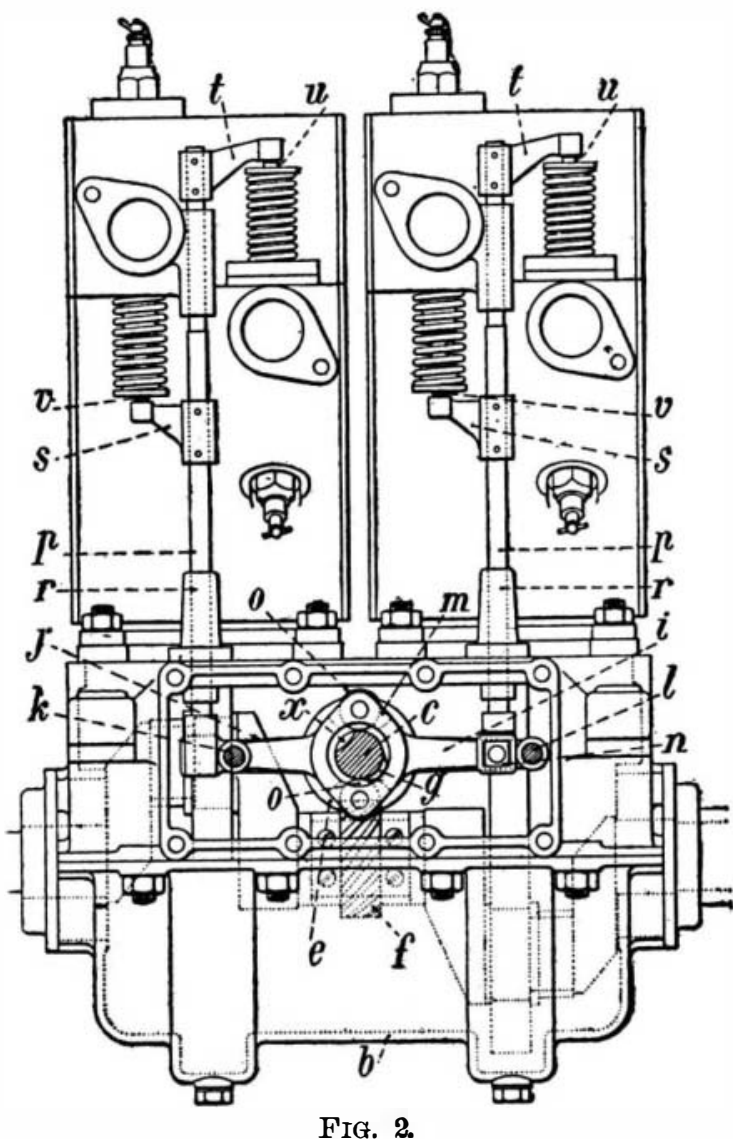

c, Transverse half-speed cam shaft; $\boldsymbol{d}$, plate carrying lever arms ; $e$,
spiral driving gears: $x, g$, depressed and raiged cams for operatting

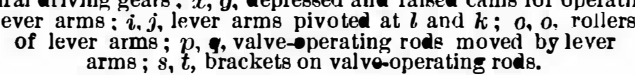

two-cylinder or a four-cylinder motor, while at the same time the number of parts is much less. The simplest form of the motor is the uplex, and by combining two of these, a bi-duplex or quadruplex motor is obtained. chambers and the effect of the explosion is transmitted to the crankshaft of the motor by a single connecting rod and a single crank. The explosions of the two cylinders are successive, like those of an ordinary twocylinder four-cycle motor, but they are distanced equally. The upper cylinder of the duplex motor works like the ordinary form of cylinder, while the lower one is made to operate practically and give an efficiency equal to that of the upper one by means of a pair of explosion chambers formed in the outer casting and containing the spark plugs as shown in Fig., 4. In the lower cylinder, when the piston arrives at the end of the stroke, its upper end reaches almost to the top of the cylinder, and the gas is practically all compressed in the outer explosion chambers. The lower cylinder thus serves only for the expansion of the gas due to
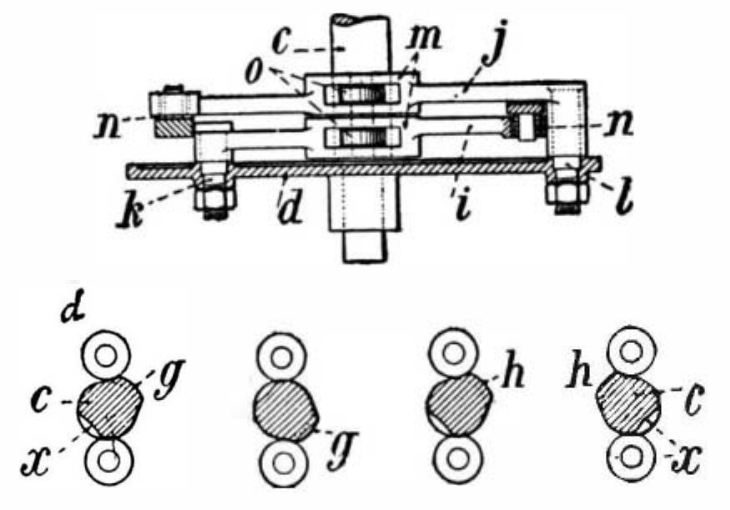

FIG. 3.-PLAN VIEW OF LEVER ARMS AND DIAGRAM SHOWING ARRANGEMENT OF FOUR DOUBLE CAMS.

\section{pivots of lever arms; $m$, annular part of lever arms carrying rollers
$n$, vertical push rods resting on lever arms ; 0 , upper rollers of}

the explosion. Care is taken to design the form of the explosion chambers so that the speed of ignition is rendered high, due to the compact form of the chamber which brings all the gas near the spark plug. The ignited gas does not surround the part of the piston which has the smaller diameter until the piston is moving downward, owing to this disposition, and moving downward, owing to this disposition, and this
part is thus prevented from heating to an abnormal degree by coming in contact with the burning gases when they are hottest.

On the above principle a double or bi-duplex motor may be formed by placing two such motors side by side The two piston rods are connected to a common crankshaft by two cranks situated at 180 deg. In this way we secure on the four-cycle principle the advantages of a 4-cylinder 4-cycle motor, but only use two 